\title{
Number of readmissions was similar for hospital at home and traditional hospital care for children with moderate illness
}

\author{
Sartain SA, Maxwell MJ, Todd PJ, et al. Randomised controlled trial comparing an acute paediatric hospital at home \\ scheme with conventional hospital care. Arch Dis Child 2002;87:371-5.
}

\section{QUESTION: Do readmissions and length of care differ for hospital at home $(\mathrm{HAH})$ and traditional hospital care $(\mathrm{HC})$ for moderately ill children with breathing difficulties, diarrhoea with or without vomiting, or a feverish illness?}

\section{Design}

Randomised \{allocation concealed\}*, unblinded, controlled trial with follow up to 90 days.

\section{Setting}

A large district general hospital in northwest England.

\section{Patients}

399 moderately ill children (mean age 25.7 mo, 60\% boys) who had breathing difficulties $(\mathrm{n}=202)$; diarrhoea with or without vomiting $(n=125)$; or a feverish illness $(n=72)$; and were likely to require $\geq 24$ hours of nursing observation. Exclusion criteria were child unsuitability as judged by the general practitioner (GP), assessing physician, or nurse; child unwillingness or inability to participate; no telephone access; or registration with a GP outside the health authority. 389 children (97\%) completed the trial.

\section{Intervention}

210 children were allocated to HAH, a nursing scheme that operated 24 hours/day, 7 days/week, and provided planned visits until 2300 hours (1-4 visits/d) and nightly on call service. Before leaving the hospital, nurses and parents planned the child's treatment and care. Nurses supported and cared for children and their families, and also educated parents to care for their children. The nurse determined discharge from $\mathrm{HAH}$ using predetermined criteria. Families had direct access to a HAH nurse within 48 hours of discharge if the symptoms recurred. 189 children were allocated to traditional inpatient HC.

\section{Main outcome measures}

Main outcome was readmission within 90 days. Secondary outcomes were accident and emergency department attendances and length of stay/care.

\section{Main results}

Analysis was by intention to treat. The HAH and HC groups did not differ for readmissions (table) or attendances at the accident and emergency department (no data available). Children in the HAH group received an extra day of care compared with those in the HC group (mean bed/care d $2.37 v 1.37, \mathrm{p}<0.001)$.

\section{Conclusion}

Number of readmissions did not differ for hospital at home and traditional hospital care for moderately ill children with breathing difficulties, diarrhoea with or without vomiting, or a feverish illness.

*Information provided by author.

\section{COMMENTARY} points should be considered when interpreting the results. may be judged. parental coping ability.
Sources of funding:

North West Regional Office and Wirral Health Authority.

For correspondence: Dr MJ Maxwell, Arrowe Park Hospital, Upton, Wirral, UK. sam.sartain@ whnt.nhs.uk

Hospital at home $(H A H) v$ traditional hospital care $(H C)$ for children with moderate illnesst

\begin{tabular}{|c|c|c|c|c|}
\hline $\begin{array}{l}\text { Outcome at } 90 \\
\text { days }\end{array}$ & HAH & $\mathrm{HC}$ & RRI $(95 \%$ CI) & NNH \\
\hline$\geq 1$ readmission & $8.1 \%$ & $7.4 \%$ & $9.3 \%(-44$ to 113$)$ & Not significant \\
\hline
\end{tabular}

Reducing hospital admission and readmission rates of children has long been an aim of child health practice in the UK. The study by Sartain $e t a l$ is important because it uses an RCT to compare the outcomes of HAH and routine HC in acutely ill children. To my knowledge, no other study has attempted to do this. However, several

The criteria for entry to the trial limited participants to children with moderate illness. In some children's units in the UK, these criteria would warrant early discharge regardless of a HAH scheme. The authors point out the social elements to these admissions according to Townsend deprivation scores and family employment status. The HAH service may therefore be viewed as a way of managing social admissions for acute illness by means of home based nursing. Whether this is a cost effective way to address the issue is not apparent from the findings presented. However, for the purposes of the RCT, the authors provide an objective set of criteria against which the 2 services (HAH and $\mathrm{HC}$ ) may be evaluated, and against which other similar services

At first glance, the hospital readmission rate appears to be a good proxy for parental ability to cope with acute illness at home. However, 2 patterns should be noted. Firstly, increased demand for treatment of respiratory distress may have resulted from improved parental recognition of respiratory symptoms. Secondly, readmission rates for children with fever, and children with diarrhoea and vomiting appear to be lower than usual readmission rates. However, as the authors point out, the group of children with the highest readmission rates had chronic health problems rather than acute episodic illness. This raises the question of whether readmission rates are, in fact, a good outcome measure, and whether they are useful as a proxy for

Interestingly, the large number of initial refusals for randomisation were because parents wanted the HAH service. The qualitative data appear to indicate high parental demand for this service. This suggests a high user preference for HAH service and could be a major impetus in service reconfiguration for acutely ill children.

David Pontin, RN, PhD Senior Lecturer, School of Maternal and Child Health University of the West of England Bristol, UK 